\title{
O PROTAGONISMO DE LÍDERES NEGROS NOS LIVROS INFANTIS APÓS A PROMULGAÇÃO DA LEI 10.639/03: RESSIGNIFICANDO VISÕES SIMPLISTAS?
}

\author{
Vívian Stefanne Soares Silva (CEFET/MG)* \\ https://orcid.org/0000-0002-6256-0017
}

\section{RESUMO}

Este trabalho propõe-se a analisar a obra Madiba, o menino africano (2011) uma narrativa biográfica que traz Nelson Mandela como personagem principal - por meio da observação dos aspectos gráficos, editoriais e enunciativos do exemplar. A partir disso, objetivamos discutir de que modo os livros infantis publicados após a promulgação da Lei 10.639/2003 tecem suas representações e, ainda, como essas representações estão atreladas às instâncias de poder, como a escola e o governo. Nossas conclusões partem da reflexão de que, embora o personagem negro figure como protagonista nesses livros, sua representação tende a ser baseada em percepções colonialistas; ademais, essas percepções inclinam-se a selecionar certos aspectos da sua trajetória que podem construir um imaginário social que vê o sujeito negro como pacífico ante as situações de racismo/preconceito. Sendo assim, embora os relatos biográficos acerca de personagens negros sejam de grande relevância social - uma vez que ressignificam o imaginário coletivo quanto à aparência e à origem do herói -, ainda se atrelam a uma representação simplista tanto da África do Sul quanto do líder político, devendo ser repensados enquanto elementos representativos dos grupos étnico-raciais nos livros literários.

Palavras-chave: literatura infantil; representação negra; lei 10.639/03; Nelson Mandela.

\section{ABSTRACT}

\section{THE PROTAGONISM OF BLACK LEADERS IN CHILDREN'S BOOKS AFTER THE ENFORCEMENT OF LAW 10.639/03: RESIGNIFYING SIMPLIST VISIONS?}

This paper aims to analyze the work Madiba, o menino africano (2011), a biographical narrative with Nelson Mandela as the main character, through the observation of graphic, editorial, and enunciative aspects of the book. Onwards

\footnotetext{
Mestre em Estudos de Linguagens pelo Centro Federal de Educação Tecnológica de Minas Gerais. CEFET/MG. Belo Horizonte, Minas Gerais, Brasil. Atualmente desenvolve pesquisas nas áreas de literatura para as crianças, edição de livros e representação negra. Está vinculada ao grupo de pesquisa Leitura Literária, Edição, Mediação e Ensino (LLEME). E-mail: vivianstefanne@gmail.com
} 
we discuss how children's books published after Law 10.639/2003 weave their representations. In addition, how these representations are tied to power instances, such as schools and government. We concluded as of pondering that although the black character appears as a protagonist in these books, his representation tends to be based on colonialist perceptions; moreover, these perceptions tend to select specific aspects of his trajectory that can build a social imaginary that sees the black subject as peaceful when faced with situations of racism/prejudice. Thus, although biographical accounts about black characters are of great social relevance - since they resignify the collective imaginary about the hero's appearance and origin - these accounts are still tied to a simplistic representation of both South Africa and the political leader and should be rethought as representative elements of racial, ethnic groups in literary books. Keywords: children's literature; black representation; law 10.639/03; Nelson Mandela.

\section{RESUMEN}

\section{EL PROTAGONISMO DE LOS LÍDERES NEGROS EN LOS LIBROS INFANTILES TRAS LA APLICACIÓN DE LA LEY 10.639 / 03: ¿RESIGNIFICANDO VISIONES SIMPLISTAS?}

Este trabajo se propone a analizar la obra Madiba, o menino africano (2011), una narrativa biográfica que trae como protagonista a Nelson Mandela, a través de la observación de los aspectos gráficos, editoriales y enunciativos del ejemplar. En base a esto, pretendemos discutir de que manera los libros infantiles publicados después de la promulgación de la Ley 10.639/2003, hacen sus representaciones y, también, cómo estas representaciones se vinculan a las instancias de poder, como la escuela y el gobierno. Nuestras conclusiones parten de la reflexión de que a pesar del personaje negro aparecer como protagonista en estos libros, su representación suele basarse en percepciones colonialistas; además, estas percepciones tienden a seleccionar ciertos aspectos de su trayectoria que pueden construir un imaginario social que ve al sujeto negro como pacífico frente a las situaciones de racismo/prejuicio. Así, aunque los reportajes biográficos sobre personajes negros son de gran relevancia social - ya que resignifican el imaginario colectivo cuanto a la apariencia y origen del héroe - estos relatos aún siguen vinculados a una representación simplista tanto de Sudáfrica como del líder político, debense repensarlos como elementos representativos de los grupos étnicos raciales en los libros literarios.

Palabras clave: literatura infantil; representación negra; ley 10.639/03; Nelson Mandela. 


\section{Introdução ${ }^{1}$}

O interesse pelas pesquisas sobre a temática literatura infantil vem consolidando-se tanto no campo literário quanto no campo editorial ${ }^{2}$. Acreditamos que esse interesse respalda-se, sobretudo, no fato de se tratar de uma literatura ampla, que acolhe formatos e possibilidades diversas e se direciona para um público em formação, ou seja, que possui potencial impacto na formação de leitores. À vista disso, esta proposta se sustenta, uma vez que engloba tanto os estudos literários quanto os estudos editoriais, buscando, por meio da análise da obra Madiba, o menino africano (2011), discutir representações sociais construídas acerca do sujeito negro, sob a ótica de algumas categorias de análise, como: percepções do continente africano; concepções colonialistas sobre o sujeito negro; e representações do negro numa postura pacífica frente às diversas violências as quais ainda é submetido.

Para tanto, nos pautamos num marco temporal que se inicia com a promulgação da Lei 10.639/03, pois, após a legislação, percebe-se um crescimento das publicações que abrangem essa temática. Todavia, convém questionar se esse crescimento é apenas quantitativo ou se de fato as representações têm sido reformuladas de maneira mais abrangente, abarcando o universo plural do negro, tal como sua história e cultura. Objetivando levantar essa reflexão, propomos este trabalho.

\section{Literatura infantil: do seu surgimento à lei 10.639/03}

O surgimento dos livros infantis, tal qual os conhecemos, acontece na Inglaterra, no século $\mathrm{XVII}^{3}$. No Brasil, a tendência é acompanhar, embora a posteriori ${ }^{4}$, o caminho trilhado pe-

1 Revisão linguística e de ABNT de Carolina Quetz.

2 Os procedimentos éticos foram observados durante a realização da pesquisa que deu origem ao texto apresentado.

3 Conforme apontam Lajolo e Zilberman (2007), Coelho (1991), Hunt (2010), entre outros autores.

4 As primeiras publicações de livros para as crianças no los países europeus. Desse modo, publicações traduzidas são utilizadas principalmente para alfabetizar e desenvolver a capacidade leitora dos cidadãos. Assim, as primeiras casas editoriais brasileiras que enxergaram nesse nicho um cenário para suas produções estavam comprometidas com a publicação de livros didáticos e literários destinados à escola, potencial mercado consumidor à época. As publicações parecem, então, atender a certo molde, tanto nos aspectos gráfico-editoriais quanto nas temáticas abordadas ${ }^{5}$.

A escola é tão significativa como principal mercado consumidor dos livros direcionados para a formação infantil que interfere na logística editorial como um todo, pois, para além da produção incipiente de livros literários, há a formação de uma indústria voltada para a publicação de livros didáticos. Se os primeiros atuavam como ferramenta de apoio ao sistema escolar, os últimos são o vetor desse sistema, de modo que "o problema da publicação dos livros não se resolve com sua impressão, seja em que quantidade for, mas com a criação de um mercado para os livros. 0 desenvolvimento do sistema escolar foi criando esse mercado de massas" (CURTIS, 1977, p. 119 apud LINDOSO, 2004, p. 64, grifo do autor).

Atuando então de maneira similar àquela que é proposta aos livros didáticos, a literatura infantil está atrelada às reivindicações políticas e sociais, isto é, ao plano de nação que se

Brasil datam do século XIX (LAJOLO; ZILBERMAN, 2007).

5 Autores como Adelina Lopes Vieira, Júlia Lopes de Almeida, Figueiredo Pimentel, Olavo Bilac, Coelho Neto e Alexina Leite de Magalhães Pinto são alguns dos precursores dos livros infantis de autoria brasileira. Suas obras datam do final do século XVIII e início do século XIX e foram publicadas, majoritariamente, no eixo Rio-São Paulo. Dentre as casas editoriais que foram berço dessas publicações, destacam-se a Livraria Quaresma e a Livraria Francisco Alves. A primeira ficou conhecida por suas publicações populares, geralmente em formato de bolso; seu proprietário, Pedro da Silva Quaresma, é citado por alguns autores como o precursor da literatura infantil brasileira graças à publicação de títulos como Histórias da Carochinha (1894). A segunda ficou inicialmente conhecida pela edição e venda de livros didáticos, sendo por alguns anos o monopólio do segmento no Brasil (LAJOLO; ZILBERMAN, 2007). 
constituía naquela época. Essa condição coloca a literatura infantil sob um corrente questionamento acerca dos livros para as crianças se originarem da necessidade de se formar cidadãos, havendo, portanto, pouca liberdade criativa que fizesse correspondência com a literatura, de modo que seu projeto se assemelhava ao de qualquer outra produção sob demanda:

(...) a literatura infantil viu-se envolvida mais diretamente, a ponto de confundir-se com a meta proposta: textos foram escritos segundo o modelo da produção em série, e o escritor foi reduzido à situação de operário, fabricando, disciplinadamente, o objeto segundo as exigências do mercado (LAJOLO; ZILBERMAN, 2007, p. 117).

Embora na virada do século XIX para o século XX despontem importantes transformações literárias do ponto de vista de uma produção brasileira, esse início - atrelado aos aspectos educacionais - repercute em toda a cadeia de produção de livros infantis até os dias atuais. Esses aspectos são realçados também pela porosidade do campo editorial de produção de livros infantis frente às demandas externas, visto que se trata de uma produção direcionada a um público que tem pouca autonomia e que é "supervisionado" por instituições de poder para além da escola, como a família e o governo.

As influências dessas instituições refletem de diversas maneiras na produção dos livros para as crianças, pois, se por um lado podem em alguma medida limitar a liberdade criativa dos agentes envolvidos na produção editorial dos títulos, como os autores e os ilustradores ${ }^{6}$, por outro podem ser motivadoras, na perspectiva que as ações articuladas pelo governo também abrem espaço para temas e vertentes antes invisibilizados. Essa última percepção pode ser vista, por exemplo, com a promulgação da Lei $10.639 / 2003$, que instituiu a obrigatoriedade

6 Considerando, sobretudo, que as escolas têm acesso aos livros para as crianças por meio dos programas governamentais, os quais possuem regras predefinidas. Essa discussão pode ser observada em maior profundidade no trabalho de mestrado desenvolvido por Jéssica Tolentino, intitulado A literatura para crianças e jovens sob coerções: uma análise crítica do PNLD Literário (2020). do ensino de história e cultura afro-brasileira dentro das disciplinas que já fazem parte das grades curriculares dos ensinos fundamental e médio, entre outros.

Essa legislação tornou-se um marco nas produções literárias que traziam personagens negros como sujeitos. A medida incentivou o crescimento do número de publicações, concedendo espaço para a ampliação tanto dos temas quanto dos personagens. A partir disso, cresceram também produções que traziam como protagonistas personagens africanos e/ ou cenários decorrentes de seu continente. De certa forma, podemos pressupor que a legislação colocou em xeque as representações que emergiam dos textos infantis - as quais eram generalizadas, não incluindo a diversidade social, econômica e racial do país (LAJOLO; ZILBERMAN, 2007).

Até por volta da década de 1970, a política por trás dos livros infantis de representação negra objetivava o branqueamento da população por meio de um silenciamento das discussões étnico-raciais. Assim, os objetos culturais apontavam ou para a ausência desses sujeitos ou para sua aparição de maneira estereotipada (FRANÇA, 2006). No Brasil, tal condição era ainda mais acentuada: o país estava recentemente descomprometido com um regime escravocrata que vigorou por quase 400 anos. Após a abolição e a condenação social de atitudes racistas, o que a nação ainda incipiente buscou foi apagar o passado, o que significava não só a mitigação do fato histórico, mas também a exclusão do sujeito negro e de sua influência sobre a sociedade brasileira:

Nesta perspectiva, o silenciamento e a inferiorização da personagem negra nos textos da literatura infantojuvenil do início do século XX, bem como do período posterior, pode ser entendido como efeito da própria estrutura social marginalizante que, com o pretexto da modernização nacional, fechou as portas para a chamada "população de cor" (FRANÇA, 2006, p. 64).

Pesquisadores que se debruçam sobre os estudos acerca da representatividade do su- 
jeito negro nos livros infantis ${ }^{7}$ apontam para a percepção de que essas representações, além de demorarem muito a irromper, foram feitas de uma maneira negativa, isto é, apresentando o negro de forma estereotipada e subalterna, como aconteceu, por exemplo, em livros como Histórias de tia Anastácia (1934) e a Bonequinha preta (1938).

É importante destacar, contudo, que a promulgação da Lei 10.639/2003 foi reflexo de um movimento que já vinha ganhando consistência e espaço no Brasil e que teve seu ápice na década de 1970 com a ascensão do Movimento Negro $^{8}$ - consolidado na organização Movimento Negro Unificado (MNU), empreitada resultante de movimentações que se iniciaram na década de 1930. Essas ações refletem o amadurecimento de um projeto de mobilização social de pessoas pretas em prol de reivindicações de cunho social, educacional, cultural, entre outras, além de ir contra a discriminação e o preconceito em suas mais variadas esferas ${ }^{9}$. A consolidação desse movimento como uma agitação de massas, isto é, como uma mobilização social ampla, foi crucial para o fomento de muitas demandas raciais, entre elas a representatividade de sujeitos negros na esfera criativa do país: na arte, na literatura, na música, por exemplo. Nesse sentido, a Lei 10.639/2003 foi resposta de um requerimento já protocolado por diversas frentes que buscaram inserir as pessoas pretas em representações culturais mais amplas e expressivas.

É diante dessa perspectiva histórica que propomos a análise de uma obra que traz como cerne a representação de um importante

7 Podemos citar como exemplos os trabalhos desenvolvidos por Dupont (2013); França (2006); Moreno (2015); e Oliveira $(2003 ; 2010)$.

8 0 Movimento Negro pode ser entendido como a "luta dos negros na perspectiva de resolver seus problemas na sociedade abrangente, em particular os provenientes dos preconceitos e das discriminações raciais, que os marginalizam no mercado de trabalho, no sistema educacional, político, social e cultural" (DOMINGUES, 2007, p. 101).

9 Esse assunto é detalhadamente apresentado sob uma perspectiva histórica, fazendo referência a importantes autores e trabalhos, por Domingues no artigo "Movimento negro brasileiro: alguns apontamentos históricos” (2007). personagem negro. Para a seleção do corpus, objetivamos buscar um título biográfico ${ }^{10}$. Nossa escolha respaldou-se no fato do gênero ser comumente utilizado como ferramenta educativa quando direcionado às crianças, sobretudo porque narra uma vida ressaltando seus pontos exemplares (CARINO, 1999). Logo, acreditamos que relatar a vida de um homem negro que conquistou um lugar de destaque é, em certa medida, ressignificar o papel do sujeito negro na sociedade, inspirando as crianças negras a uma concepção mais positiva de destino/ atribuição social.

No âmbito da observação do mercado editorial, consideramos a aparente ascensão do gênero. Em recente edição da pesquisa Retratos da Leitura no Brasil, realizada pelo Instituto Pró -Livro em parceria com o Itaú Cultural (2020), o livro Diário de um banana figura como um dos mais citados pelos leitores quando perguntados acerca da última obra que leram ou estão lendo, o que demonstra o interesse das crianças e jovens por histórias circunscritas no espaço biográfico ${ }^{11}$. A mesma pesquisa aponta que, embora em uma quantidade menor, leitores do $1^{\circ}$ ao $9^{\circ}$ ano recorreram ao gênero biográfico quando perguntados sobre qual tipo de livro haviam lido no último ano. Esses dados demonstram que o interesse por narrativas de vida, sejam elas autobiografias, biografias e diários, existe no Brasil e ainda que entre seu público há a presença significativa de crianças.

\section{Apresentação da obra}

Madiba, o menino africano (2011) é um livro escrito por Rogério de Andrade Barbosa, pesquisador de literatura africana e afro-brasileira, e ilustrado pelo professor e artista visual Renato Alarcão. Publicado pela Cortez Editora, o

10 Entendendo por biografia a "narração oral, escrita ou visual dos fatos particulares das várias fases da vida de uma pessoa ou personagem" (COSTA, 2012, p. 51).

11 Segundo Leonor Arfuch (2010, p. 60), um espaço contemporâneo composto por "biografias, (...) autobiografias, memórias, testemunhos, histórias de vida, diários íntimos - e, melhor ainda, secretos - , correspondências, cadernos de notas". 
exemplar concentra-se, sobretudo, na narrativa dos anos iniciais da vida de Nelson Mandela, importante líder negro, internacionalmente (re)conhecido.

Nelson Rolihlahla Mandela, protagonista do título, nasceu em Mvezo, pequena aldeia africana, em 18 de julho de 1918. Embora criado em uma sociedade aparentemente desvinculada das questões políticas, Mandela se viu logo jovem morando na frenética Joanesburgo, maior cidade da África do Sul, e fazendo parte da Liga da Juventude - veia jovem do Congresso Nacional Africano (CNA), partido político que fazia frente ao sistema que ficou mundialmente conhecido como apartheid ${ }^{12}$.

Mandela liderou uma série de campanhas, boicotes e greves em nome do CNA, tornandose líder da UmkhontoweSizwe (MK) [Lança da Nação], o braço armado do partido. Por esse motivo foi preso em 1964 junto com outros amigos e também integrantes do grupo, sendo condenado à prisão perpétua. Sua condenação histórica marcou sua trajetória como principal líder político na luta contra o apartheid. Após mais de 27 anos de prisão, Mandela foi libertado em 11 de fevereiro de 1990. Em 1994, entrou novamente para a história ao se tornar o primeiro presidente negro da África do Sul, eleito por meio de eleições democráticas.

O livro, Madiba, o menino africano (2011), concentra-se principalmente na narrativa dos anos iniciais da vida de Mandela, os quais são detalhados com mais profundidade do que sua vida adulta. 0 título é catalogado como infantil/ juvenil, o que aponta para uma classificação híbrida. Predominantemente visual, a obra pode ser categorizada, conforme Graça Ramos (2011), como um livro com ilustrações.

12 Instituído pela população europeia após a colonização da África do Sul, o sistema ergueu-se inicialmente sob a prerrogativa de que os povos nativos não brancos, bantus, deveriam ser separados do povo europeu, bôeres ou africâners, a fim de preservar suas tradições. Desse modo, até mesmo os grupos étnicos compostos por imigrantes, como os indianos, eram colocados à margem pela população branca. Todavia, a escolha pela implantação do regime sustentava-se, sobretudo, na ideia de superioridade da raça branca frente às outras raças.
O título enquadra-se bem na linha editorial da editora que está, desde seu surgimento, alinhada à produção intelectual, pontuando sua relação com a educação e o desejo de fomento nesse campo. Nesse sentido, seu catálogo dedica-se às publicações infantojuvenis, que indicam ter sido projetadas para integrar o currículo escolar, dividindo-se em categorias como "Adolescência - mudança" e "Temas escolares". 0 mesmo catálogo dá espaço para as biografias, que atualmente são 17.

A editora afirma, ainda, estar atenta às legislações que geram impacto nos catálogos escolares, como a Lei 10.639/2003; isso pode ser observado por meio dos títulos publicados que retratam não só a cultura africana, mas também a cultura indígena. A política editorial da Cortez também preza por obras nacionais, havendo poucas traduções no catálogo.

À vista disso, a obra Madiba, o menino africano (2011) é uma proposta que não está desvinculada de projetos maiores almejados pela instituição. Segundo a editora, o exemplar integrará a futura coleção Quem foi?, projeto de médio prazo que visa adicionar ao catálogo da casa editorial uma coleção voltada para a produção de biografias (CORTEZ, 2019). Assim, o título nasce observando o nicho de mercado ocasionado pela legislação vigente e visando trabalhos futuros. Embora com algumas produções com enfoque na representatividade negra, percebemos que esse não é o principal objetivo de atuação da editora, a qual se concentra nas obras teóricas; todavia, parece que a editora reconhece a existência de uma demanda prévia e demonstra atendê-la por meio dessas publicações.

Do ponto de vista gráfico-editorial da obra, o livro apresenta um número incontável de representações que se sustentam tanto no texto verbal quanto nas ilustrações, o que corrobora a ideia de Pinheiro (2018), em seu artigo "O diálogo entre texto escrito, ilustração e projeto gráfico em livros de literatura infantil premiados", em que a autora destaca a importância das imagens e do projeto gráfico nos livros 
para as crianças, elementos entendidos como importantes vetores na construção de sentido.

\section{Proposta de análise}

Madiba, o menino africano (2011) é uma narrativa predominantemente visual, em que as imagens constantemente carregam referências extratextuais. De formato retangular vertical $\left(21 \mathrm{~cm} \times 28 \mathrm{~cm}^{13}\right)$, o mais comum nas obras infantis, a narrativa apresenta capa composta por uma icônica ilustração: um menino seminu, de pés descalços, correndo num campo aberto rumo a uma sequência de baobás.

Figura 1 - Madiba, o menino africano

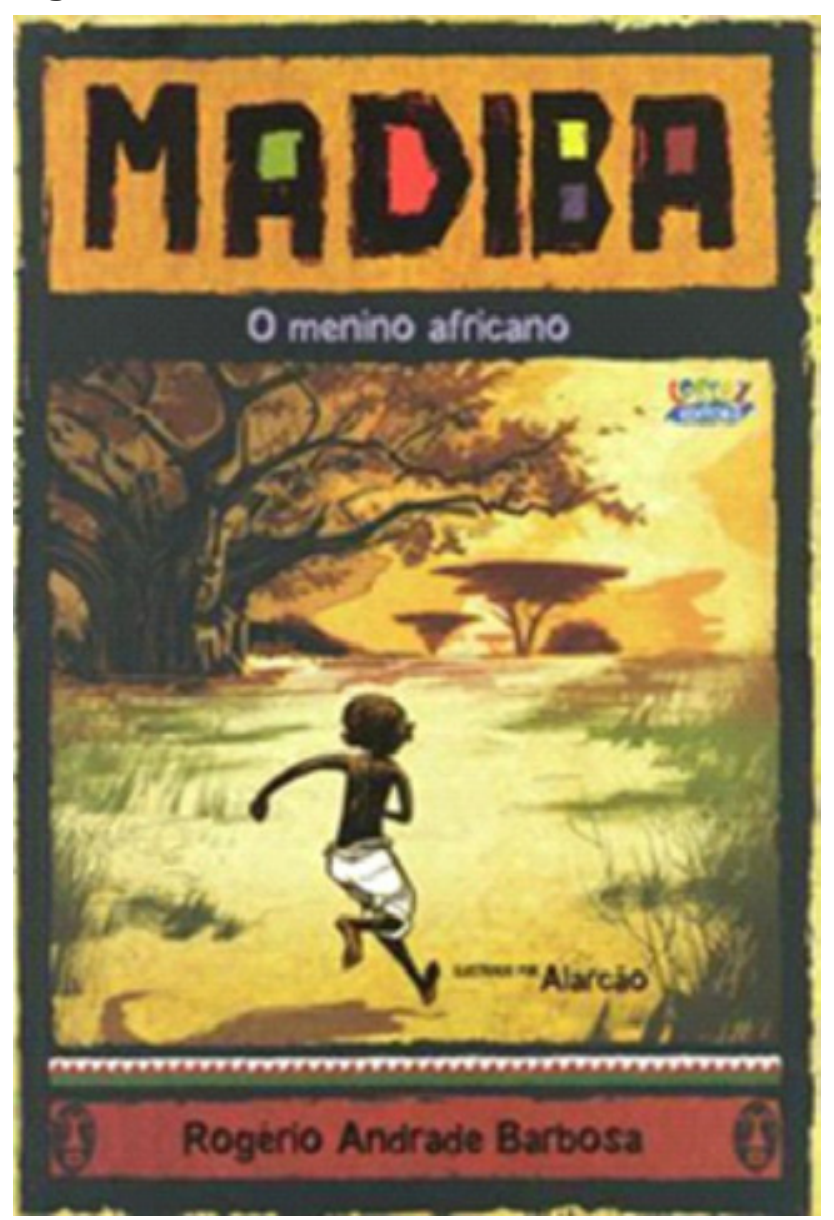

Fonte: Cortez Editora

O título nominal composto informa-nos o nome do protagonista do livro, o qual aparece

13 Nossa referência para essa classificação baseia-se na proposta de Hendel (2003, p. 35), o qual aponta que "o primeiro número é a largura e o segundo, a altura" do livro. adjetivado pelo epíteto "o menino africano". A utilização de epítetos nos títulos dos livros é "um dispositivo narrativo didático" (LINDEN, 2011, p. 309), uma vez que fornece informações sobre o conteúdo do livro, estimulando a formação de percepções acerca da obra. A menos que se tenha o conhecimento prévio de que Madiba é o apelido carinhoso concedido a Nelson Mandela pelos africanos, ainda não é possível prever de que se trata de uma obra biográfica sobre o personagem.

A capa do exemplar traz muitas outras "pistas" literárias. 0 baobá, por exemplo, é uma árvore oriunda do continente africano. De dimensões exponenciais, a árvore que pode permanecer viva por séculos é tida por muitos africanos como a árvore da vida, devido à sua magnitude e força. A admiração por essa árvore ultrapassa questões de apreço, estando relacionada às tradições culturais africanas que encontram no baobá significações espirituais. A presença da árvore na ilustração faz uma referência implícita ao continente africano e simboliza a força e a longevidade do personagem.

O uso das cores no título, por sua vez, aponta tanto para a diversidade como faz referência à bandeira da África do Sul, na qual estão presentes os tons de vermelho, amarelo, preto e verde. Os nomes do autor e do ilustrador ocupam posições distintas na obra; embora o exemplar seja predominantemente ilustrado, o nome do autor recebe ênfase na capa, escrito em uma fonte maior e centralizado, enquanto a menção ao ilustrador fica alinhada à direita, em fonte menor. Isso pode revelar certo desequilíbrio quanto à participação na autoria do livro que, colocada desse modo, aponta não ter sido compartilhada.

A ilustração de capa faz menção ainda à paisagem rural, característica do campo, e a uma vida livre, representada pela corrida desprendida do menino. $\mathrm{O}$ apelido do personagem que aparece centralizado na margem superior da página, em negrito, é composto por uma fonte não identificada que remete à pintura, 
dando a ideia de arte/trabalho manual; além disso, o uso de traços grossos e a redação em caixa-alta exprimem força. A composição parece contrastar a fragilidade da criança com a força evocada dos outros elementos apresentados. Essa percepção corrobora-se logo na primeira página da narrativa, a qual introduz um "menino predestinado a ser líder do seu país" (BARBOSA, 2011, p. 5).

Neste trecho narrativo, notamos uma percepção da obra biográfica muito utilizada em livros que se constroem como proposta de textos inspiradores ou de formação, isto é, biografias que são utilizadas como exemplos de vida na educação de jovens leitores. A percepção que se destaca é a de que Mandela já nasceu predestinado a se líder de seu país, não houve uma escolha, aquele já era seu destino e ele estava sujeito a ele. Esta percepção é criticada por alguns autores, tais como Dosse (2015) e Barthes (2001), porque se embasa no mito de que a história de vida de um sujeito é algo predestinado, partindo do pressuposto que a vida é uma linha linear de acontecimentos e não uma sequência difusa de escolhas, na maioria das vezes arbitrárias, que acabam nos levando a certa direção. Todavia, utilizar a narrativa biográfica enfatizando certa predestinação ao sucesso é uma forma de motivar os jovens leitores ao alcance de futuros brilhantes.

A folha de guarda e a folha de rosto da obra reiteram a ilustração de capa e o título da narrativa (figura 2). A única mudança é que o menino agora corre olhando para a frente, com um semblante feliz. Dessa maneira, estabelece-se maior proximidade entre personagem e leitor. Além disso, o contraste entre essas duas perspectivas demonstra a dupla caracterização do protagonista, que ora é descrito como uma criança "comum", ora como um menino "especial”, um futuro herói do seu povo. Vê-se ainda que o personagem está com uma vara nas mãos, concepção que de início pode nos levar a pensar que o garoto se dedica aos trabalhos do campo ou que está a brincar no campo. Todavia, numa análise secundária, podemos dizer que essa imagem de Mandela como pastor remete também à figura do pastor de ovelhas difundida pelo Cristianismo, "aquele que vem para salvar o seu rebanho".

Figura 2-Folha de rosto

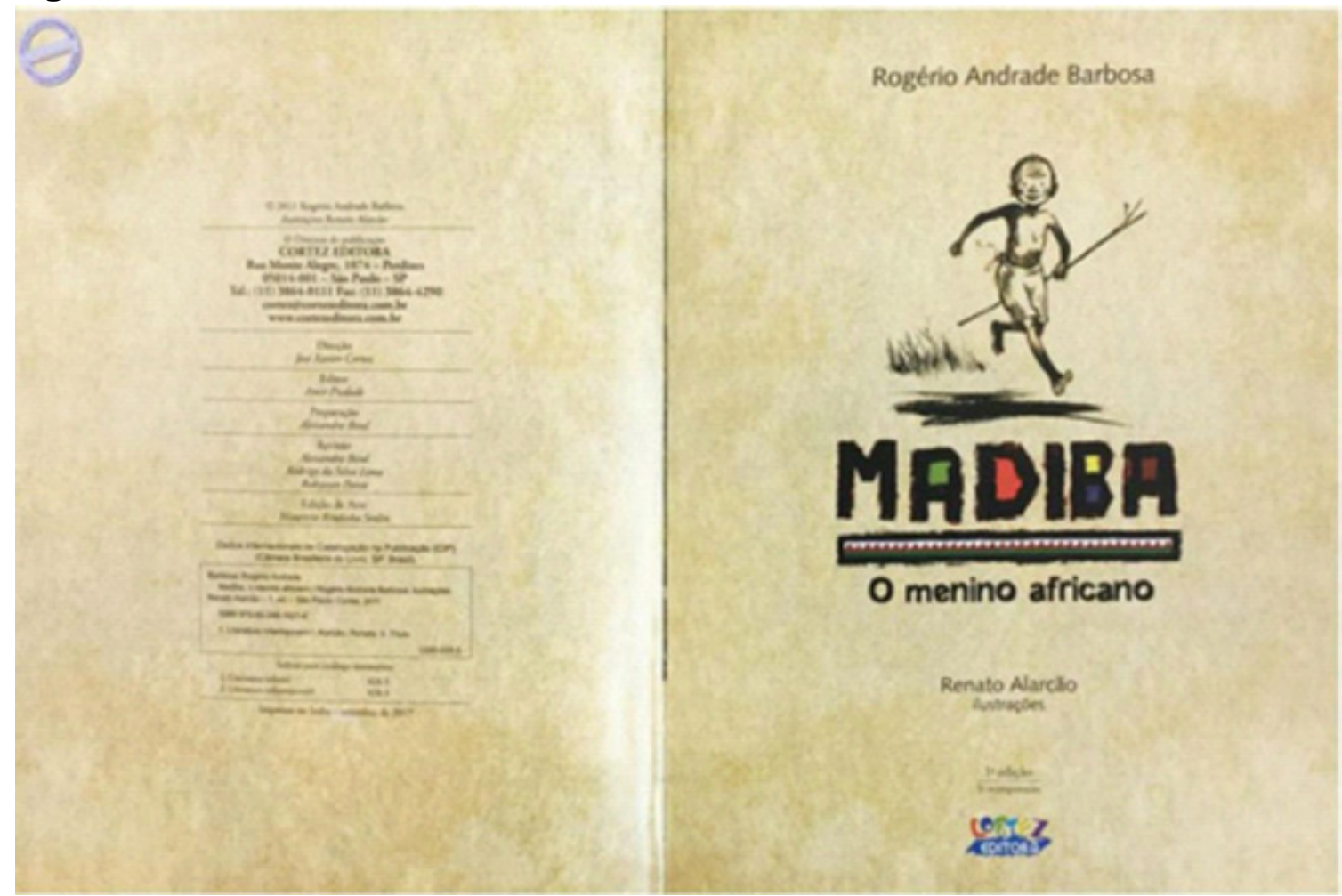

Fonte: Cortez Editora 
A narrativa inicia-se com paginação dupla e uma imagem panorâmica que apresenta uma paisagem bastante verde rodeada por colinas, sendo composta por árvores, um rio e pequenas cabanas. Abaixo, do lado esquerdo da imagem, observamos um homem/ menino com uma vara nas mãos pastoreando ovelhas. Se não fosse pela troca dos trajes, teríamos a conexão com a imagem de folha de rosto e contracapa, inferindo que o garoto é um pastor de ovelhas. 0 texto verbal nos conta que o lugar apresentado pelas imagens é Mvezo, uma aldeia no interior da África do Sul.

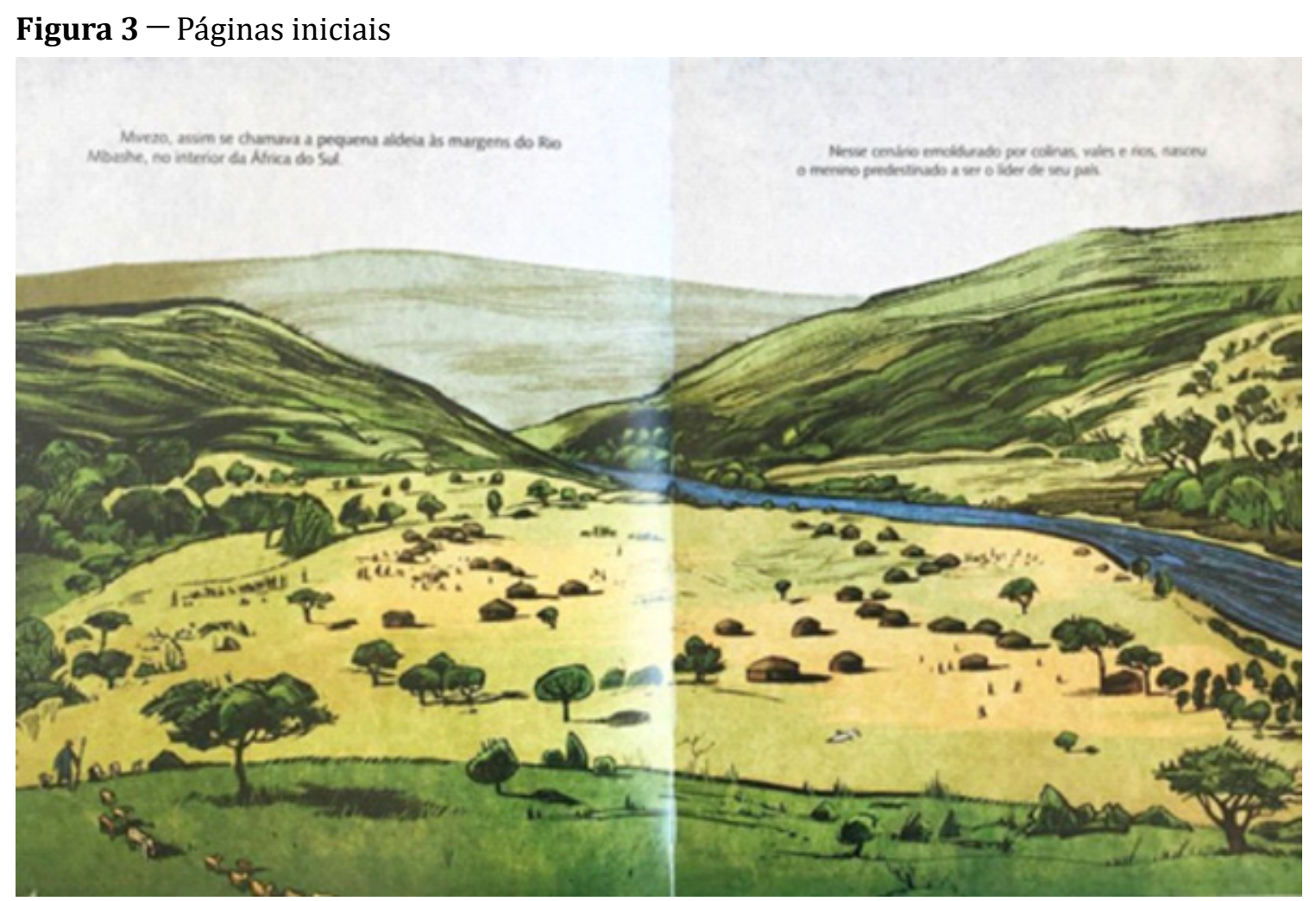

Fonte: Cortez Editora

A imagem da figura 3 apresenta uma África do Sul essencialmente rural, embora ela traga a representação do lugar em que Mandela nasceu e passou os primeiros anos de sua infância, essa ideia do continente africano como um espaço primitivo é exposta outras vezes na narrativa e sustenta conceitos historicamente utilizados para alegar que os africanos eram genericamente incapazes de terem "refinamentos civilizados", o que justificava sua servidão. Stuart Hall (2016, p. 162) aponta que os africanos "identificados com a natureza simbolizavam o 'primitivo' em contraste com o mundo civilizado" e que essa percepção dava margem à instituição de políticas racializadas, as quais subjugavam a organização e a cultura do povo negro.
Do ponto de vista da análise gráfica da obra, a relação estabelecida entre texto e imagem no decorrer da narrativa varia de colaborativa para redundante, entendendo que a redundância, segundo Linden (2011), não presume repetição, mas sim que texto e imagem convergem para uma mesma significação narrativa. Características tipográficas aparentemente não interferem na construção narrativa.

O livro organiza-se inicialmente sob uma diagramação associativa, texto e imagem dividem o mesmo espaço, embora o texto figure ou acima ou abaixo da página buscando "não interferir" nas imagens. As ilustrações que seguem panorâmicas utilizam cores fortes e parecem apontar para o estilo "linha nítida", desenvolvido por Linden (2011, p. 40); nele as 
formas de cores densas são contornadas por uma linha preta, que varia quanto à espessura. 0 estilo traz uma espécie de dramaticidade para as ilustrações.

A próxima dupla de páginas apresenta o nome do garoto, Rolihlahla, dando ênfase para o significado do nome, que em Xhosa quer dizer "o encrenqueiro". As ilustrações reiteram a ideia de que se trata de um menino travesso e corajoso ao apresentá-lo destemidamente subindo em uma árvore. Esta colocação reforça o fato de que até pelo nome Mandela foi uma pessoa predestinada, quando, na verdade, é improvável que o nome escolhido no nascimento de uma pessoa reflita nos rumos de seu destino. Algumas páginas à frente, a narrativa esclarece que o garoto cuidava de ovelhas, amarrando a pista da imagem apre- sentada na folha de rosto e na primeira página (o menino com uma vara nas mãos correndo pelo campo).

0 povo africano é retratado de maneira simples, embora o texto verbal afirme que o pai do garoto era "descendente de uma linhagem de poderosos chefes" (BARBOSA, 2011, p. 9). A imagem que apresenta a família do menino ilustra uma tradicional família africana, numerosa em quantidade, tanto de esposas quanto de filhos, ao mesmo tempo em que lança mão de uma variedade de cores para compor as roupas utilizadas. Destaca-se ainda a soberania do homem, o pai, o qual é protegido pelo guarda-chuva de uma das esposas e é o único a estar sentado no que aparenta ser um trono, enquanto todos os outros se colocam ao seu redor, sentados no chão ou em pé.

Figura 4-Texto x Ilustração

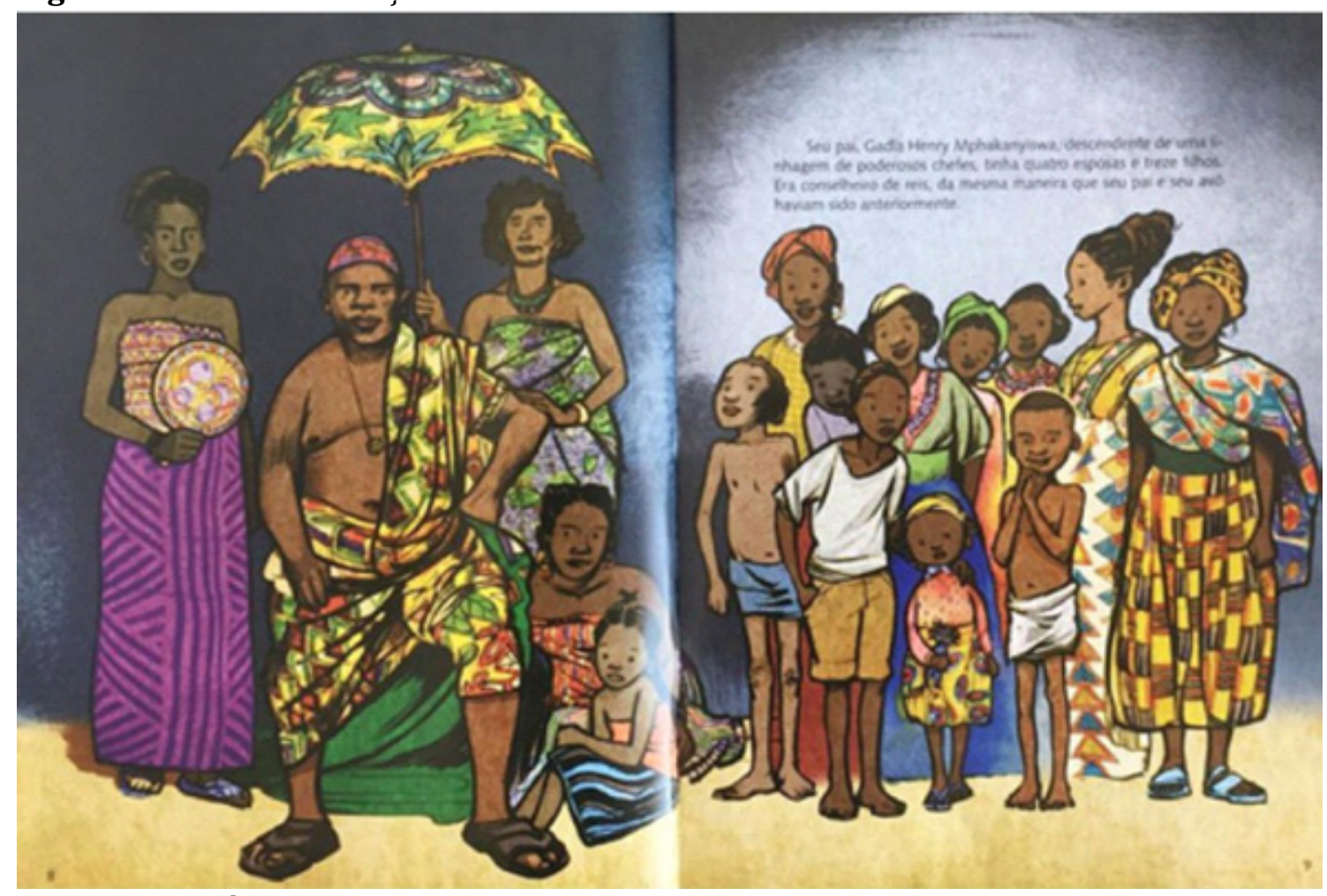

Fonte: Cortez Editora

Nesta imagem podemos notar novamente uma representação do continente africano atrelado a um contexto de simplicidade, pois, embora o pai de Mandela seja elencado como um importante ocupante na cadeia de governo da tribo a qual pertencia, seus filhos aparecem descalços, com roupas simples e em numerosa quantidade, imagem que evoca a ideia de pobreza. Em momento algum o texto verbal ressalta questões relacionadas às tradições ou à cultura africana, de modo que é possível construir ou reforçar por meio da observação 
da imagem a concepção de que a África do Sul é um continente predominantemente pobre, em que até as pessoas que pertencem às linhagens de poder aparentam ser desprovidas de recursos financeiros. Assim, a representação de alguns elementos naturais na vivência de pessoas oriundas das tribos africanas pode ser um possível reforço ao mito de uma África do Sul carente, sobretudo, porque os recursos naturais - grandes fontes de riqueza das populações tribais - não são citados no texto.

As páginas continuam a narrar a infância de Rolihlahla, apresentando uma comunidade exclusivamente negra, o que contrasta com a existência de outras etnias na África do Sul. Deste modo, a representação da Àfrica do Sul na narrativa não está atrelada à ideia de um país multirracial. 0 livro realça as ações violentas das pessoas brancas enquanto descreve a população como formada predominantemente por pessoas negras. Esse aspecto tende a reforçar a diferença, apresentando brancos e negros em posições acentuadamente opostas. Segundo Hall (2016), este tipo de construção baseada em oposições binárias pode intensificar as relações de poder. Ademais, determina que todos os brancos compactuavam com o regime de segregação racial e que só haviam negros sendo subjugados, quando na verdade a população africana é multirracial, e o CNA era composto por líderes de origem branca, negra, indiana, etc., os quais foram até mesmo condenados em conjunto com Nelson Mandela.

À medida que a narrativa evolui, as páginas deixam de ser duplas para serem únicas, dando dinamicidade ao tempo de leitura. À certa altura, a obra faz uma representação explícita da África como espaço mítico (figura 5), interpretação que já podia ser inferida por meio da inserção de elementos como o baobá, mas é reiterada quando a narrativa ilustra Mandela ouvindo as histórias de sua avó, as quais são representadas por animais, cores, iluminação, elementos que parecem se originar do cadeirão que está ao fogo. Essa ilustração reforça a ideia da África como um lugar primitivo.
Figura 5-A África como espaço mítico

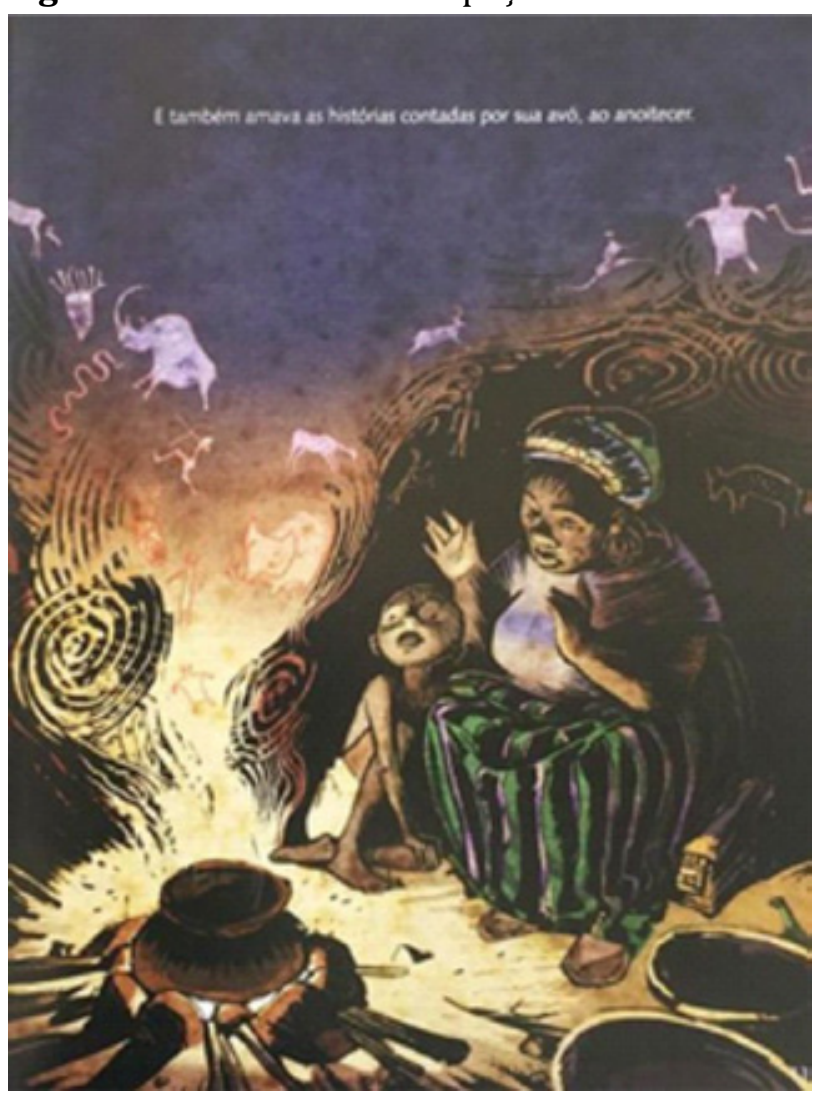

Fonte: Cortez Editora

O menino continua sendo retratado sob o viés de uma vida humilde. Ao narrar, por exemplo, que ele foi o primeiro dos 13 filhos de seu pai a frequentar uma escola, o texto emenda que "como não possuía roupas adequadas, nos primeiros dias de aula, o garoto teve de usar uma calça de seu pai cortada até os joelhos e amarrada com um cordão na cintura para não cair" (BARBOSA, 2011, p. 15). Essa caracterização ajuda a construir o caráter do personagem: é um menino obstinado, alguém que, apesar das dificuldades, estava feliz por estudar. Isso também segue um tipo de narrativa bastante popular: a do homem que "veio do nada" e trilhou uma trajetória admirável. Na mesma cena, surge o primeiro personagem branco, a professora de Mandela, cujo primeiro ato descrito pela narrativa é alterar o nome dele, chamando-o de Nelson, um nome britânico. Nesse trecho, deparamo-nos com a representação da violência simbólica do sistema que alterava até a identidade do sujeito. 
Ademais, a obra traz outra significação ideológica ao apresentar Mandela como o primeiro de sua família a frequentar uma escola, dando ênfase à sua infância enquanto reitera que, embora de origem simples, Mandela alçou um lugar de destaque. Essa representação tende a estabelecer um ensinamento moral, o qual consiste na ideia de que, independentemente de onde o sujeito venha ou da sua condição social, ele é capaz de concretizar seus planos/ sonhos, uma imagem que remete ao mito da meritocracia.

Há, então, um grande salto temporal e as funções do texto mudam, colaborando para esclarecer a ordem em que os acontecimentos ocorreram (função de ordenação, segundo Linden [2011]). Rapidamente, a narrativa nos informa que Nelson está em Joanesburgo, seu país passa por um regime de segregação racial e ele se formou. A diagramação da página também é alterada, intercalando entre associação e compartimentação (quando o espaço da página é dividido - não necessariamente de maneira literal — em sequências de imagens). Esse tipo de diagramação altera o ritmo da narrativa, tornando-o mais acelerado (figura 6).

Diferentemente do modo gradual como ocorreu a alteração da disposição das imagens no início da narrativa, passando de imagens panorâmicas a imagens de uma página e somente depois "vinhetas", é de maneira brusca que as ilustrações voltam a ser panorâmicas, o que dá a impressão de que a história está voltando ao seu ritmo inicial. A narrativa parece tender a acelerar os momentos de conflito do personagem, dando enfoque à sua infância livre. Isso pode demonstrar, por um lado, o desejo dos autores de que o leitor-criança se identifique com o personagem. Por outro lado, pode revelar certa concepção de infância. Ou, ainda, que talvez os conflitos são evitados/apressados porque entende-se que esse assunto não é apropriado para as crianças.
Figura 6-Compartimentação da narrativa

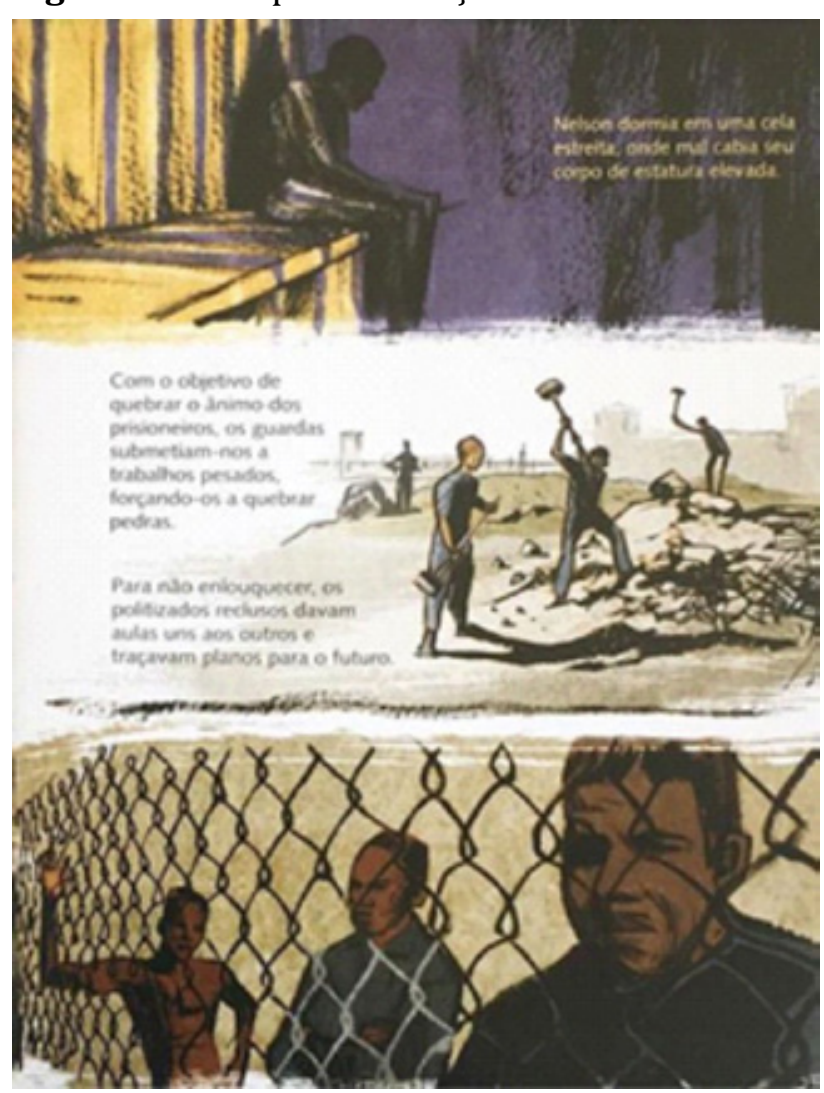

Fonte: Cortez Editora

A última página assume uma diagramação que até então não havia sido disposta no livro. Há uma ênfase à página nobre ${ }^{14}$, enquanto texto e imagem aparecem dissociados. Tanto texto verbal quanto ilustração retomam representações dadas no início da narrativa: o texto ressalta "o encrenqueiro", e a imagem ilustra no campo aberto o menino pastoreando com uma ovelha no colo (figura 7). 0 desfecho é, então, um retorno aos elementos iniciais, ressaltando que, após esses acontecimentos, Mandela continua com os mesmos princípios que nortearam sua infância.

Observamos neste ponto, sobretudo na imagem de pastor, o destaque que a narrativa tende a dar ao caráter pacífico e complacente de Mandela em detrimento de seu posicionamento ativo e, arriscamos dizer, violento na luta. Essas imagens evocam representações perigosas, posto que o poder aqui é entendido muito mais em sua dimensão simbólica do que

14 A página nobre é tida como a página direita do livro aberto; trata-se daquela para a qual nosso olhar se dirige primeiro. 
Figura 7-A representação de Mandela como pastor

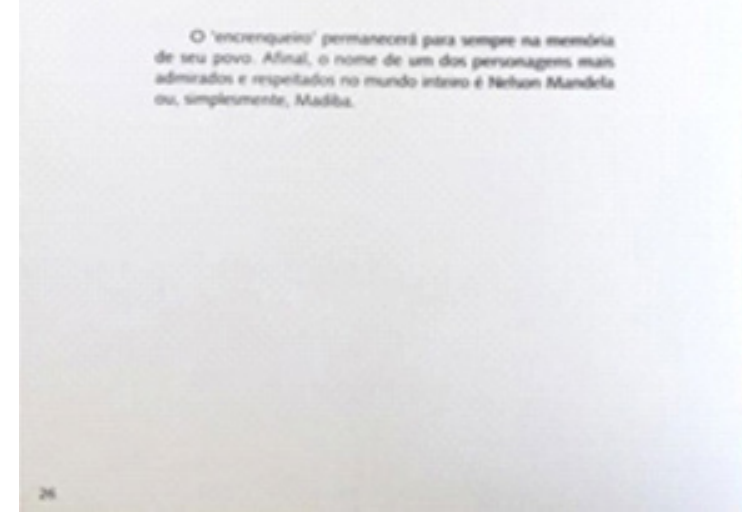

Fonte: Cortez Editora

em sua conotação em termos de coesão ou violência. Trata-se, sobretudo, "do poder de representar alguém ou alguma coisa de certa maneira - dentro de um determinado 'regime de representação'” (HALL, 2016, p. 193).

Importante considerar, ainda, que diante de um sistema agressivo e brutal tal como o apartheid, a luta pacífica não foi uma vontade do ativista, o qual se responsabilizou, sobretudo, pela liderança do grupo que iniciou a luta armada. Percepções nesse sentido podem influenciar crianças negras a agir com complacência diante do racismo ou do preconceito, demonstrando que esse é o único caminho para a vitória, quando na verdade, em muitas situações, a denúncia e a luta são determinantes.

\section{Considerações finais}

Stuart Hall (2016) entende o conceito de discurso como elemento pelo qual a linguagem se materializa e a linguagem como a forma pela qual compartilhamos os sentidos construídos culturalmente, os quais carregam nossas representações sobre as coisas, objetos, indivíduos e acontecimentos. Desse modo, podemos

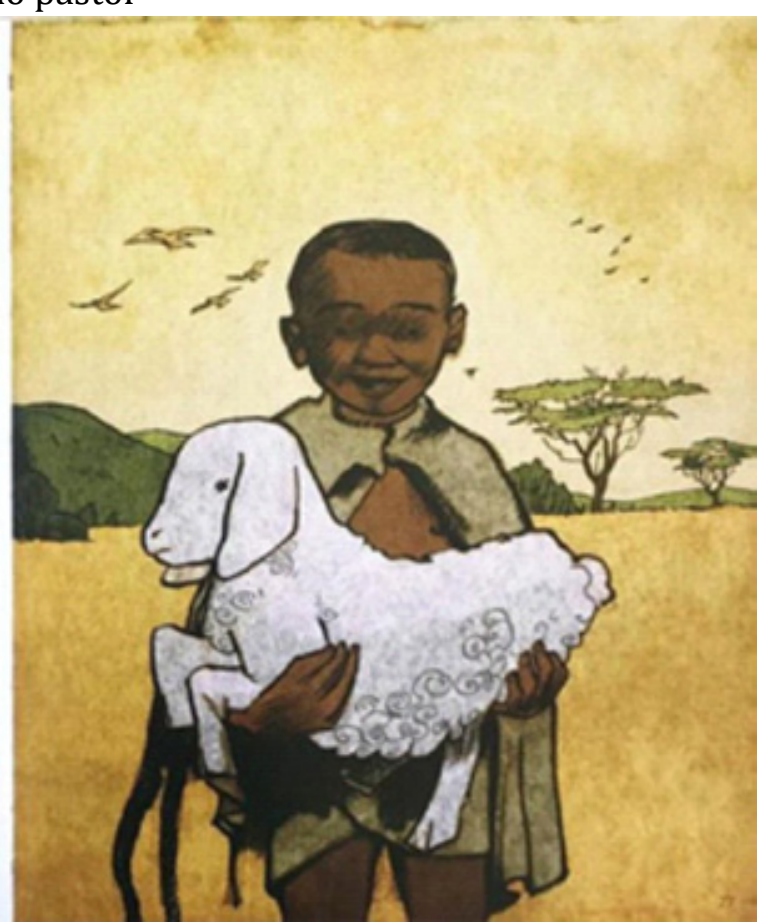

interpretar as imagens, os textos e o projeto gráfico dos livros como maneiras pelas quais os discursos se materializam nessas obras. Essa prática de linguagem, composta por esses elementos, visa "expressar ou transmitir um pensamento, um conceito, uma ideia, um sentimento" (HALL, 2016, p. 24). Todavia, as representações não podem ser interpretadas apenas pelo que dizem; é necessário observar também o que fica oculto, isto é, os aspectos que se situam fora dos "fragmentos" escolhidos para tecer a vida de Mandela, uma vez que "a representação funciona tanto no que não é mostrado quanto no que é mostrado" (HALL, 2016, p. 105).

A importância dessas representações reside, sobretudo, na relação que elas mantêm com o poder. Não se trata de saber se uma imagem é verdadeira ou não, se algo de fato aconteceu ou não - até porque os fatos são inalcançáveis, a verdade é sempre uma representação. Mas se o conhecimento difundido culturalmente estabelece algo como fato, sendo legitimado por uma instância de poder ${ }^{15}$, dificilmente esta

150 poder aqui é entendido muito mais em sua dimensão simbólica do que em sua conotação em termos de coesão 
ideia, ainda que não exista nenhuma comprovação conclusiva sobre ela, será posta à prova. Assim, o ditado que afirma que "conhecimento é poder" é extremamente relevante nesse contexto, pois se há como determinar a trajetória de um homem, as características de um povo, a existência ou não de determinado movimento, há o poder para determinar o que as pessoas conhecerão sobre esse homem, qual a imagem elas construirão sobre esse povo e quais movimentos virão ou não à tona no alinhavo da história.

Nossa análise corrobora a percepção inicial de que as imagens são importantes construtoras de sentido nos livros infantis, de modo que sua utilização reside na capacidade de evocar símbolos interiorizados em nossa cultura. $\mathrm{Na}$ obra analisada, por exemplo, observamos que, embora Mandela seja descrito, por meio do texto verbal, como uma criança pobre e pertencente ao campo, são as imagens que evocam em nós a ideia de pastor, tal como construída pelo Cristianismo. Dessa maneira, a observação de um menino de roupas simples correndo pelo campo, com uma ovelha no colo ou com uma vara nas mãos, remete-nos ao mito do pastor que veio para salvar seu povo, suas ovelhas. Além disso, diz respeito também ao caráter de simplicidade e pacificidade atribuídos ao líder.

0 fato dessa narrativa, em específico, estar inserida numa casa editorial, a Cortez Editora, que possui uma predisposição para publicar exemplares que potencialmente irão circular em escolas, leva-nos a questionar essas representações com ainda mais potencialidade. Isso porque, como dissemos, as instâncias de poder, especialmente o governo por meio dos editais de aquisição de livros, ditam as regras que, em certa medida, não abarcam a forma como as representações são feitas, possibilitando que os títulos circulem sem que haja sobre eles esse julgamento de valor.

ou violência. Trata-se, sobretudo, "do poder de representar alguém ou alguma coisa de certa maneira - dentro de um determinado 'regime de representação'" (HALL, 2016, p. 193).
As representações do continente africano na obra sustentam-se na concepção de uma África do Sul de origem simples e rural, aspectos contrários a elementos como o progresso, a tecnologia e o desenvolvimento, o que reforça que o espaço africano concentra-se no campo e na criação de animais. Esse mito reitera um lugar de subalternidade para os africanos, de modo que pressupõe que eles são menos civilizados ou desenvolvidos, sendo, portanto, incapazes de evoluírem. 0 caráter pacífico de Mandela adotado pela narrativa alinha-se a essa concepção, apresentando o menino, sobretudo, na imagem de pastor de ovelhas, em detrimento de sua atuação como advogado e sua ênfase a importância dos estudos e do conhecimento, elementos tidos por Mandela como capazes de levar seu povo à libertação

À vista dessas colocações, notamos que a representatividade e a forma como ela é construída são muito importantes, pois apenas aumentar o universo de produções - ainda que favoreça o crescimento da bibliodiversidade - não desconstrói representações que estruturam e legitimam visões simplistas da África e dos africanos, e na perspectiva da diáspora, dos negros brasileiros.

Assim, a percepção destas construções e de suas limitações é crucial para a educação, pois são esses livros que formarão o imaginário social das crianças e que guiarão suas experiências, excepcionalmente considerando a capacidade educativa da obra biográfica. Assim, convém pensarmos para quais instâncias convém divulgar a imagem de que os negros devem crescer valorizando a passividade diante de um sistema que os oprime e os condena à marginalidade social, implicando um aumento de coerções e censuras específicas.

\section{REFERÊNCIAS}

ARFUCH, Leonor. 0 espaço biográfico: dilemas da subjetividade contemporânea. Tradução Paloma Vidal. Rio de Janeiro: EdUERJ, 2010.

BARBOSA, Rogério Andrade. Madiba, o menino 
africano. Ilustração Renato Alarcão. São Paulo: Cortez, 2011.

BARTHES, Roland. Sade, Fourier, Loyola. São Paulo: Martins Fontes, 2005.

BRASIL. Lei 10.639/2003, de 9 de janeiro de 2003. Altera a Lei no 9. 394, de 20

de dezembro de 1996. Diário Oficial da União: Brasília, DF, 10 jan. 2003. Disponível em: <http:// www.planalto.gov.br/ccivil_03/leis/2003/110.639. htm>. Acesso em: 15 ago. 2020.

CARINO, Jonaedson. A biografia e sua instrumentalidade educativa. Educação \& Sociedade, São Paulo, v. 20, n. 67, p. 153-181, ago. 1999. Disponível em: <https://www.scielo.br/pdf/es/ v20n67/v20n67a05.pdf>. Acesso em: 4 mai. 2019.

COELHO, Nelly Novaes. Panorama histórico da literatura infantil/juvenil: das origens indoeuropeias ao Brasil contemporâneo. São Paulo: Ática, 1991.

CORTEZ. [Entrevista cedida à] Vívian Stefanne Soares Silva. Belo Horizonte, ago. 2019

COSTA, Sérgio Roberto. Dicionário de gêneros textuais. Belo Horizonte: Autêntica Editora, 2012.

DOMINGUES, Petrônio. Movimento negro brasileiro: alguns apontamentos históricos. Tempo, v.12, n. 23, p.100-122, 2007. Disponível em: <https://www.scielo.br/j/tem/a/yCLBRQ5s6VT N6ngRXQy4Hqn/?lang=pt\&format=pdf $>$. Acesso em: 13 nov. 2020.

DOSSE, François. 0 desafio biográfico, escrever uma vida. 2. ed. Tradução Gilson César Cardoso de Souza. São Paulo: EDUSP, 2015.

DUPONT, Vera Regina Vargas. A criança negra na literatura infantil brasileira contemporânea. 2013. Dissertação (Mestrado em Linguagem e Sociedade) - Universidade Estadual do Oeste do Paraná, Cascavel, 2013. Disponível em: <http:// tede.unioeste.br/bitstream/tede/2345/1/vera_ regina_vargas_dupont.pdf $>$. Acesso em: 10 nov. 2020.

FRANÇA, Luiz Fernando de. Personagens negras na literatura infantil brasileira: da manutenção à desconstrução do estereótipo. 2006. Dissertação (Mestrado em Estudos de Linguagens) Universidade Federal de Mato Grosso, Cuiabá, 2006. Disponível em: <http://www.dominiopublico.gov. br/download/texto/cp036455.pdf>. Acesso em: 10 nov. 2020.
HALL, Stuart. Cultura e representação. Tradução Daniel Miranda, William Oliveira. Rio de Janeiro: Editora PUC-Rio, Apicuri, 2016.

HENDEL, Richard. 0 design do livro. Tradução Geraldo Gerson de Souza, Lucio Manfredi. São Paulo: Ateliê Editorial, 2003.

HUNT, Peter. Crítica, teoria e literatura infantil. Tradução Cid Knipel. São Paulo: Cosac Naify, 2010.

LAJOLO, Marisa; ZILBERMAN, Regina. Literatura infantil brasileira: história e histórias. São Paulo: Editora Ática, 2007.

LINDEN, Sophie Van der. Para ler o livro ilustrado. São Paulo: Cosac Naify, 2011.

LINDOSO, Felipe. 0 Brasil pode ser um país de leitores? Política para a cultura - política para o livro. São Paulo: Summus Editorial, 2004.

MORENo, Jenny Lorena. o negro e a diferença nos livros de literatura infantil veiculados no Programa Nacional Biblioteca da Escola. 2015. Dissertação (Mestrado em Educação) - Universidade Federal do Rio Grande, Rio Grande, 2015. Disponível em: <http:// repositorio.furg.br/bitstream/handle/1/6186/ jenny $\% 20$ lorena $\% 20-\% 20$ o\%20negro $\% 20$ e $\% 20$ a $\% 20$ diferena $\% 2$ nos $\% 2$ livros $\% 20$ de $\% 20$ literatura $\% 20 \mathrm{infantil} \% 20$ veiculados $\% 20 \mathrm{no} \% 20$ programa $\% 20$ nacional $\% 2$ biblioteca $\% 20$ da $\% 20$ escola.pdf? sequence=1>. Acesso em: 11 nov. 2019.

OLIVEIRA, Maria Anória de Jesus. Negros personagens nas narrativas literárias infanto-juvenis brasileiras: 1979-1989. 2003. Dissertação (Mestrado em Educação) - Universidade do Estado da Bahia, Salvador, 2003.

OLIVEIRA, Maria Anória de Jesus. Personagens negros na literatura infanto-juvenil no Brasil e em Moçambique (2000-2007): entrelaçadas vozes tecendo negritudes. 2010. Tese (Doutorado em Literatura e Cultura) - Universidade Federal da Paraíba, João Pessoa, 2010. Disponível em: <https://repositorio.ufpb.br/jspui/bitstream/ tede/6163/1/arquivototal.pdf.> Acesso em: 10 nov. 2019.

PINHEIRO, Marta. 0 diálogo entre texto escrito, ilustração e projeto gráfico em livros de literatura infantil premiados. In: OLIVEIRA, Luiz Henrique Silva de; MOREIRA, Wagner. (orgs). Edição e Crítica. Belo Horizonte: CEFET-MG, 2018. Disponível em: <https://www.letras.bh.cefetmg. br/wp-content/uploads/sites/193/2019/04/ 
EDI\%C3\%87\%C3\%830-CR\%C3\%8DTICA-PDF.pd $\mathrm{f}$ ?fbclid=IwAR0 wXCLVaMgVDNgp3GFX4KVwU4s RGJ7Wo23Ht_jy4jUe_sR3xarM1qPTXjM>. Acesso em: 11 nov. 2019.

RAMOS, Graça. A imagem nos livros infantis: caminhos para ler o texto visual. Belo Horizonte: Autêntica Editora, 2011.
TOLENTINO, Jéssica M. Andrade. A literatura para crianças e jovens sob coerções: uma análise crítica do PNLD Literário. 2020. Dissertação (Mestrado em Estudos de Linguagem) - Centro Federal de Educação Tecnológica de Minas Gerais, Belo Horizonte, 2020.

Recebido em: 05/03/2021

Aprovado em: 31/05/2021

(cc) BY-No Este é um artigo publicado em acesso aberto sob uma licença Creative Commons. 